Available online on 15.02.2020 at http://jddtonline.info
Open Access to Pharmacentical and Medical Research
unrestricted non-commercial use, provided the original work is properly cited

Open Access

Short Communication

\title{
Malocclusion and Hair Loss: An Intimate Relationship
}

\section{Dye Brian CDT}

Owner, President, Classone Orthodontic Lab, 215 Froelich Rd, Kelowna, BC V1X 3M6, Canada

\begin{abstract}
In the dental industry, it seem no one has entertained the thought that if a dislocated mandible, in a Class II Skeletal relation could occlude or block the blood flow in in the STA.* Therefore stopping or impeding blood flow to the vertex of the head and therefor causing balding. Taking into consideration that in a healthy Class I Skeletal relation the clearance between the base of the skull and the eminence of the condyle is only $3.5 \mathrm{~mm}$. ${ }^{\text {ic } 1}$ Orthodontic experience tells us that mandibles $3.5 \mathrm{~mm}$ retrognathic and more are very common. The intent of this paper is to expose the facts and evidence that show the Class II Skeletal mandible is the cause of balding by blocking blood flow through the S.T.A. Balding of vertex can be avoided. A large array of research has been, and continues to be conducted to determine the causative agent for hair loss. Traditionally such investigation has focused on a number of varying topics, including but not limited to chromosome com position, genotype, and subsequent phenotype expression. However, little or no investigation has been conducted to deduce what effect the skeletal relationship has upon the initial development of hair loss. Through a series of observational case studies, it is evident that there is a relationship between malocclusion and hair loss. Specifically, through analysis of dental records, cephalometric radiographs, and visual observation of patients, there appears to be a correlation between Class II Skeletal malocclusion and subsequent hair loss. Further investigation yields that vascular anatomical differences between different skeletal schemes is associated with the development of hair loss.
\end{abstract}

Keywords: Craniofacial Anomalies, Pediatric Dentistry, Orthodontics, Hair Loss, Baldness

Article Info: Received 30 Nov 2019; Review Completed 19 Jan 2020; $\quad$ Accepted 28 Jan 2020; Available online 15 Feb 2020

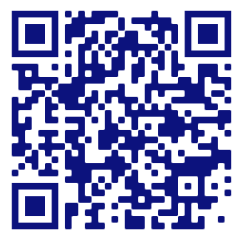

\section{Cite this article as:}

Dye BCDT, Malocclusion and Hair Loss: An Intimate Relationship, Journal of Drug Delivery and Therapeutics. 2020; 10 (1s):182-184 http://dx.doi.org/10.22270/jddt.v10i1-s.3875

*Address for Correspondence:

Dye Brian CDT, Owner, President, Classone Orthodontic Lab, 215 Froelich Rd, Kelowna, BC V1X 3M6, Canada

\section{INTRODUCTION:}

Despite overwhelming evidence highlighting the importance of vascular perfusion to the scalp in order to circumvent hair loss, little research has been conducted regarding the varying anatomical vascular landscape of the scalp. Namely, there are differences in the vascular anatomical landscape of the scalp, given varying occlusal schemes.

It is clear that the superior temporal artery (STA) $1,2,3,4$ represents $85 \%$ of the vascular supply to the scalp, whilst the remaining $15 \%$ is provided by the occipital artery (OA). In healthy Class I skeletal relationship (Figure 1), there is adequate clearance $(3.5 \mathrm{~mm})$ between the base of the skull, and the eminence of the condyle, to allow for adequate perfusion of the scalp by the STA ${ }^{5}$. However, in the instance of Class II Skeletal malocclusion, there is the possibility of reduced perfusion or occluded blood flow in the STA, due to the retrognathic architecture of the skull. Evaluation of the population reveals that hair loss is seen overwhelmingly among individuals with Class II skeletal profile, supporting the hypothesis that malocclusion leading to reduced vascular perfusion of the scalp in turn results in hair loss.

\section{METHODS:}

In order to evaluate the connection between the bald patient, and their corresponding occlusion ${ }^{6,7}$, a retrospective analysis was conducted. Specifically, the occlusion of men suffering from hair loss was evaluated through visual observation, dental models, as well skeletal cephalometric radiographs $6,8,9$. In order to limit confounding factors, only those individuals with no prior experience of orthodontic treatment were selected. Additionally, a minimum age of thirty years was selected for inclusion in this retrospective analysis. A total of one hundred individuals suffering from hair loss were selected for inclusion, and served as the experimental group.

With respect to the control group, only those individuals with no prior experience of orthodontic treatment, with a minimum age of thirty years, and with Class III Skeletal jaw relation were selected for inclusion. A total of fifty individuals with no hair loss were selected for inclusion, and served as the control group. 


\section{RESULTS:}

Of the one hundred individuals suffering from hair loss, direct visual, and observation of dental model occlusion demonstrated that ninety-six individuals had Class II dental malocclusion. However, a more thorough evaluation of the one hundred individuals, those with or without Class II dental malocclusion, through analysis of their skeletal cephalometric radiographs, reveals that all one hundred subjects selected for inclusion present with Class II skeletal malocclusion.

Of the fifty individuals presenting with no hair loss, all subjects present with a Class III skeletal relationship, upon evaluation of their dental and skeletal occlusal records.

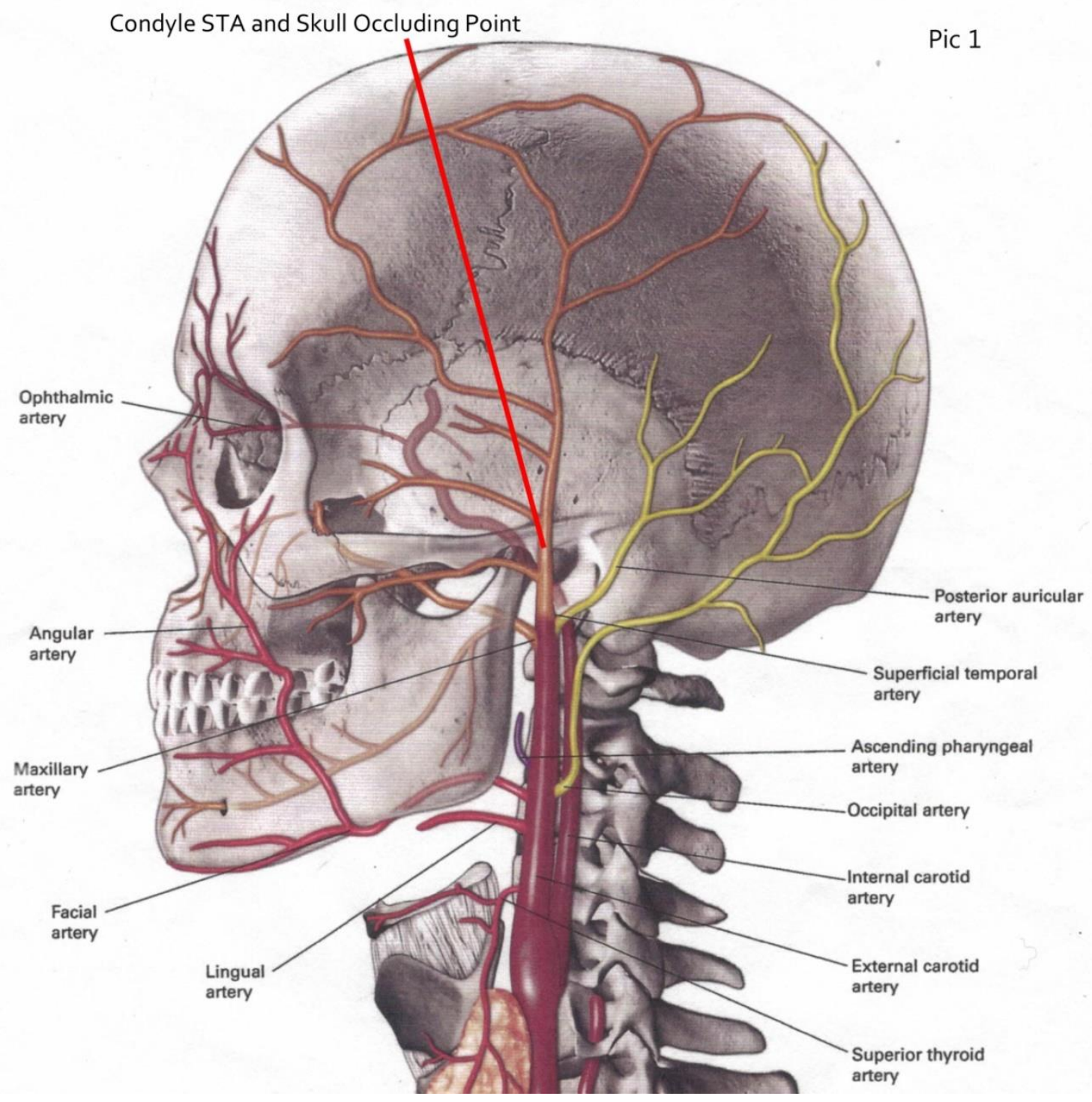

Figure 1:

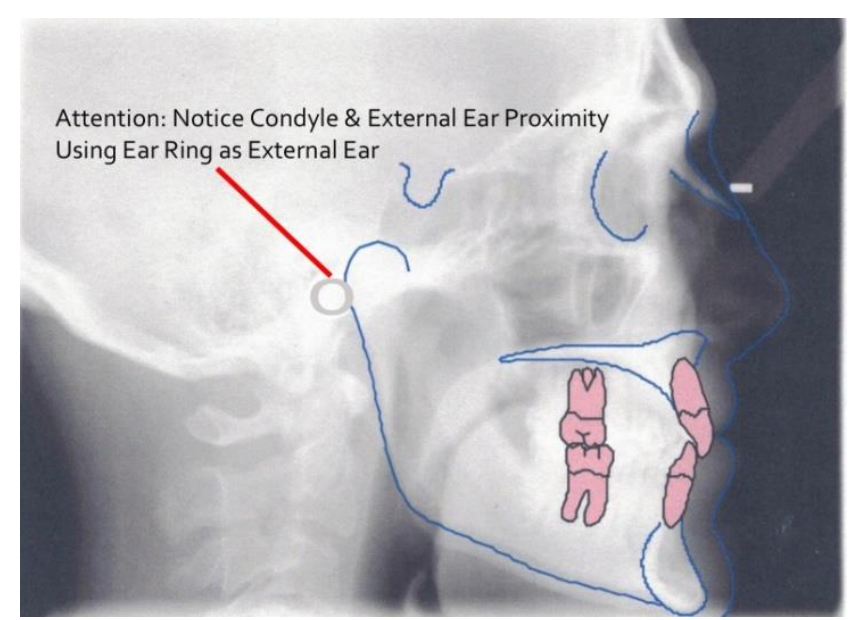

Figure 2: Skeletal Class II 


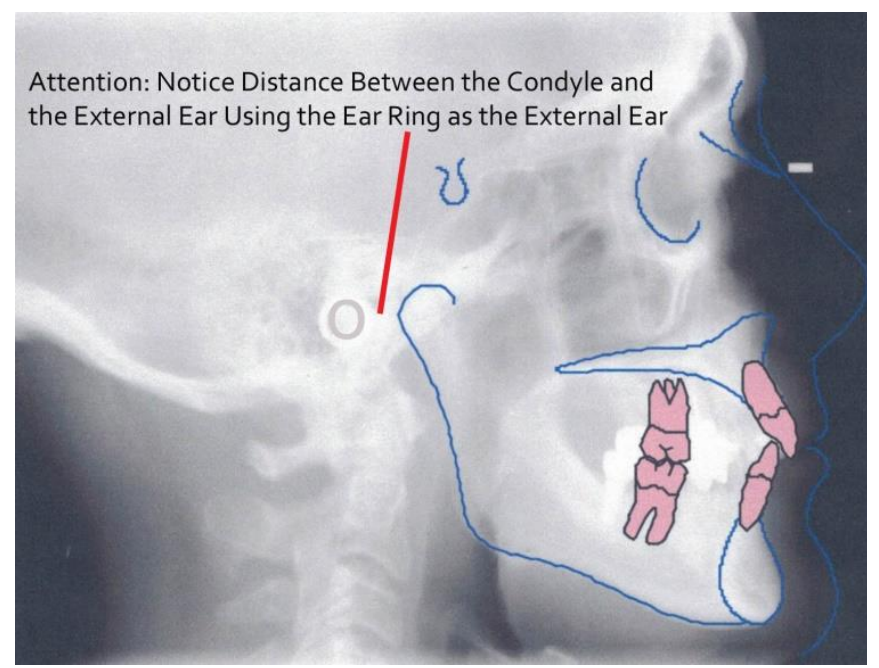

Figure 3: Skeletal Class III

\section{DISCUSSION:}

In past research, much focus has been given to the possible genetic component involved in the hair loss process. However, such research has failed to address the role of the skeletal relationship, which of course is a reflection of genetics $8,10,11$. Similar to how malocclusion, and the skeletal relationship has been proven to contribute to TMJ issues, and sleep apnea, focus should be given to address the contribution the skeletal relationship has upon development of baldness.

As Dentistry shifts towards a more conservative approach, focusing on prevention prior to intervention, a similar approach should be utilized to prevent hair loss. Namely, with knowledge of the association between Class II skeletal relationship and hair loss, greater precedence should be given to correct the skeletal relationship, and malocclusion. In doing so, the functionality and esthetics of the dentition is enhanced, whilst eliminating the occlusion of the superior temporal artery, allowing for the majority of the vascular perfusion of the scalp to be maintained, circumventing hair loss.

\section{REFERENCES:}

1. "Superficial Temporal Artery." Wikipedia, Wikimedia Foundation, 18 Mar. 2018,

en.wikipedia.org/wiki/Superficial_temporal_artery. 22 March, 2018.

2. "Aneurysms of the Superficial Temporal Artery." British Journal of Plastic Surgery, Churchill Livingstone, 14 Apr. 2005, www.sciencedirect.com/science/article/pii/000712267690004 7. 22 March, 2018 .

3. KAWABORI, Masahito, et al. "Spontaneous Giant Aneurysm of the Superficial Temporal Artery." Neurologia Medico-Chirurgica, The Japan Neurosurgical Society, 25 May 2009,

www.jstage.jst.go.jp/article/nmc/49/5/49_5_198/_article. 23

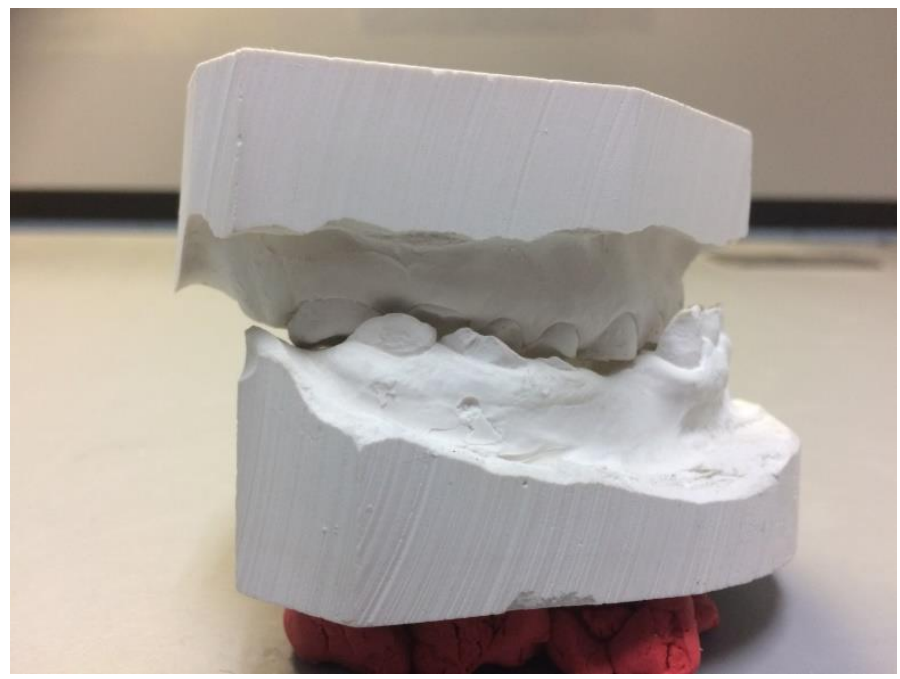

Figure 4: Exception to Rule

March, 2018

4. Takemoto, Yushin, et al. Surgical Neurology International, Medknow Publications \& Media Pvt Ltd, 2016 www.ncbi.nlm.nih.gov/pmc/articles/PMC4828951/\#sec14title, Conclusion/Article Info-Surg Neurol Int. 2016 Published online 2016 April 1.DOI:10.4103/2152-7806.179586 Authors Yushin Takemoto, Shu Hasegawa; Michiko Magamine: Daiki Kashimo, Junichi Kuratsu. 22 March 2018.

5. "A True Aneurysm of the Superficial Temporal Artery: Is There an Underlying Pre-Disposition to Such Rarities?" International Journal of Surgery Case Reports, Elsevier, 16 May 2013, www.sciencedirect.com/science/article/pii/S22102612130016 85. 22 March, 2018.

6. Kim, Pius Joon-Young. "Quantitative Assessment of Class 2 Malocclusion in Mixed Dentition." Division of Graduate Orthodontics, summary and conclusion, p. 15 ., www.collectionscanada.gc.ca/obj/s4/f2/dsk2/ftp04/mq21091. pdf.

7. Ngam, Peter, He, Hong. “Class III Malocclusion." Class III Malocclusion - an Overview / ScienceDirect Topics, www.sciencedirect.com/topics/medicine-and-dentistry/classiii-malocclusion. 23 March, 2018

8. "Class 2 Division 2 Malocclusion: Genetics or Environment Images Source." Rudolph's Pediatrics, 23rd Edition, by Mark W Kline, McGraw-Hill Education.

9. "Occipital Artery." Occipital Artery - an Overview / ScienceDirect Topics, www.sciencedirect.com/topics/veterinary-science-andveterinary-medicine/occipital-artery. 22 March, 2018

10. Freitas, et al. "Cephalometric Characterization of Skeletal Class II, Division 1 Malocclusion in White Brazilian Subjects." Journal of Applied Oral Science, Faculdade De Odontologia De Bauru - USP, www.scielo.br/scielo.php?script=sci_arttext\&pid=S167877572005000200020. 22 March, 2018

11.“Class 2 Malocclusion in Mixed Dentition.” The Journal of Clinical Pediatric Dentistry, vol. 19, no. 1, 1994, www.rondeauseminars.com/images/. 23 March, 2018 